\title{
Análise do planejamento como dispositivo mediador de mudanças institucionais com base em um estudo de caso
}

\author{
Analysis of planning as a mediating device \\ for institutional changes, based on a case study
}

Rosana Onocko Campos 1

\footnotetext{
1 Departamento de Medicina Preventiva e Social, Faculdade de Ciências Médicas, Universidade Estadual de Campinas. Rua Américo de Campos 93 , Campinas, $S P$ 13083-040, Brasil. rosanaoc@mpc.com.br
}

\begin{abstract}
This study analyzes the role of planning technologies in a changing institutional environment in which they are involved as a space for mediation. This is a qualitative study, in which planning technologies were compared with theoretical landmarks in public health. A case study was conducted at the Cândido Ferreira Health Service in Campinas, São Paulo State, Brazil. By way of conclusions, the author proposes a methodological approach to stimulate the use of planning technologies as a device for institutional change. The focus is on the importance of planning in establishing a dialogue with other theoretical corpora, such as institutional analysis, psychoanalysis, and public health.
\end{abstract}

Key words Institutional Changes; Health Planning; Planning

Resumo Este trabalho analisa o papel de tecnologias de planejamento num contexto de mudança institucional, situando-as no espaço de mediação. Trata-se de uma pesquisa de caráter qualitativo, na qual se analisaram tecnologias de planejamento em relação a um referencial teórico da saúde coletiva, valendo-se de um estudo de caso sobre o Serviço de Saúde Cândido Ferreira (Campinas, São Paulo). Esboça-se uma proposta de abordagem metodológica, visando subsidiar tecnologias de planejamento como dispositivo viabilizador de mudanças institucionais. Enfatiza-se a importância de a área do planejamento dialogar com outros corpos teóricos: análise institucional, psicanálise, saúde pública etc.

Palavras-chave Mudanças Institucionais; Planejamento em Saúde; Planejamento 


\section{Introdução}

Os métodos de planejamento têm sido apresentados como tecnologias potentes para articular mudanças no campo da saúde. O propósito declarado das correntes de Planejamento Estratégico é o de viabilizar e promover mudanças (Matus, 1993; Testa, 1995).

Com o propósito de avaliar tecnologias de planejamento no espaço de mediação, procurou-se analisar o resultado de quatro anos de oficinas de planejamento em uma instituição que passou por uma reformulação radical no seu modo de produzir ações de saúde. Estudaram-se os documentos elaborados em todas as oficinas de planejamento realizadas entre os anos 1992-1996 no Serviço de Saúde Cândido Ferreira (SSCF), Campinas, São Paulo.

Analisar tecnologias de planejamento no interior do espaço de mediação requer recuperar as articulações e inter-relações que precisam acontecer para que uma mudança tenha lugar. O que preenche esse espaço? O que faz a ponte entre diretrizes políticas e práticas reformuladas? É isso o que estamos chamando de mediação. E o planejamento, na qualidade de tecnologia, declara-se potente para tecê-la.

No caso das instituições assistenciais de saúde, essas questões encontram-se profundamente interligadas à mudança efetiva do modelo de atenção vigente. O modo concreto, segundo o qual as práticas se organizam em um momento dado, é, sem dúvida, a cristalização de uma mediação entre política e práticas (Campos, 1994). Portanto, a questão que colocamos em relação às tecnologias de planejamento refere-se a sua capacidade de quebrar essa cristalização, promovendo outras formas de organização do trabalho.

\section{Metodologia}

Do manicômio ao serviço de saúde: descrição do caso do Serviço de Saúde Cândido Ferreira

O sanatório Dr. Cândido Ferreira nasceu em 1924 com o nome de Hospício para Dementes Pobres do Arraial de Sousas. Em meados de 1990, a população de pacientes internados era constituída principalmente por idosos com muitos anos de internação - mais de $50 \%$ se encontravam internados havia mais de dez anos -, e a rotatividade da clientela era feita utilizandose apenas 25 leitos: uma clássica estrutura asilar, com certo grau de humanização. Em maio de 1990, foi assinado um convênio de co-ges- tão com a Secretaria Municipal de Saúde de Campinas, com o objetivo de resgatar o caráter público do hospital e transformar o modelo assistencial vigente. Propunha-se a criação de um espaço de tratamento para saúde mental, superando o modelo manicomial. Criaram-se, assim, as Unidades de Produção: Hospital-Dia, Núcleo de Oficinas de Trabalho, Internação de Agudos, Unidade de Moradores e Áreas-Meio.

A nova divisão do trabalho proposta assentava-se em equipes multiprofissionais, eliminando os departamentos verticais tradicionais (médico, de enfermagem etc.), e instituía o gerenciamento colegiado da instituição (Campos, 1992). Logo após essa intervenção da Secretaria de Saúde, o SSCF ganhou uma nova estrutura interna, na qual a gestão democrática e descentralizada constituía o eixo central da proposta, que se mantém até hoje.

O SSCF, apesar de ser uma entidade filantrópica, somente assiste pacientes do SUS, de Campinas e região. Essa caraterística de público/não estatal tem permitido à instituição superar as crises decorrentes das mudanças políticas e manter viável o projeto inicial. Resistindo às mudanças de cenário, o SSCF tem conseguido preservar o rumo do projeto e oferece assistência a aproximadamente quatrocentos pacientes (dos quais 130 são pacientes moradores). Além das unidades assistenciais, inaugurou-se uma escola - em convênio com a Fundação Municipal de Educação de Campinas -, um centro de convivência, um jornal e um ateliê de artes plásticas, cujas obras foram premiadas em várias mostras nacionais.

Alguns pacientes ex-moradores voltaram a viver com suas famílias após décadas de internação, e há atualmente dez moradias extra-hospitalares que hospedam quarenta e cinco pacientes com longas histórias de tratamento asilar. Vários pacientes recuperaram sua identidade civil (60), conseguindo nova carteira de identidade e o usufruto do benefício de ação continuada do INSS (49), num caminho claramente direcionado para a reconstrução da cidadania. Outros recebem seu salário da participação da renda produzida pelo Núcleo de Oficinas de Trabalho.

No percurso desta investigação, tentar-se-á demonstrar como (e se) o planejamento contribuiu para mediar essas mudanças, fazendoas possíveis.

\section{Periodização/processamento dos dados}

Analisaram-se todos os documentos produzidos pelas oficinas de planejamento realizadas no SSCF desde 1992 até 1996. Constatou-se que 
todas estavam documentadas com um grau de detalhamento adequado.

O propósito de avaliar o potencial de mediação das tecnologias de planejamento determinou a escolha de se estudar as unidadesfins, ou seja, aquelas que refletem diretamente, nas suas práticas assistenciais, as mudanças no modo concreto de organizar o trabalho e de lidar com os doentes. No SSCF, o planejamento se firmou como um procedimento sistemático a partir de 1992, momento em que a estrutura interna da instituição já tinha sido transformada e que já tinha funcionando, há quase dois anos, as equipes multiprofissionais e o colegiado de gestão. Ressaltamos essa questão para esclarecer que tais mudanças permitiram o estabelecimento de um processo de planejamento sistemático, incluindo todas as unidades de produção (Campos, 1992) e suas equipes num ambiente de participação. O planejamento veio preencher uma demanda de operacionalizar mudanças, num terreno fértil à participação, no qual as diretrizes gerais já tinham sido colocadas pela intervenção da Secretaria de Saúde, tendo como pano de fundo a reforma psiquiátrica brasileira.

Em todas as oficinas de planejamento, as equipes trabalharam definindo imagens-objetivo, problemas e operações; assim, organizouse, o material empírico respeitando esse formato, e os pares operações/problemas foram tratados em conjunto.

Analisaram-se separadamente as seqüências cronológicas das imagens-objetivo, e procurou-se a presença de problemas e/ou operações que remetessem às linhas de análise em cada unidade assistencial.

\section{As fases da pesquisa/enquadramento teórico}

Os documentos produzidos pelas oficinas de planejamento foram a principal fonte empírica analisada. A metodologia empregada foi qualitativa, realizada em duas fases:

\section{- Fase analítica}

Nessa fase procedeu-se à divisão do material empírico em um ordenamento temático, considerando-se linhas de análise pré-estabelecidas. A escolha dessas linhas foi determinada pela delimitação do objeto, procurando-se confrontar as tecnologias de planejamento com questões dilemáticas e centrais para a mudança de modelo assistencial. Essas categorias constituíram as matrizes da investigação, confrontando-se com elas, permanentemente, os achados do empírico. Como toda escolha de categorias, esta supôs um certo a priori do investigador: as linhas utilizadas fogem das categorias mais comumente trabalhadas pelo planejamento. Nesse sentido, analisou-se o planejamento com categorias alheias, porém, baseadas em categorias e conceitos centrais ao debate sobre as mudanças e impasses na saúde coletiva, que focalizam o desafio da mudança de modelo assistencial. Se o planejamento se propõe a mediar mudanças, ele tem que se manter compromissado com os fins institucionais, com a produção de saúde e com a instituição de novas formas de cuidados.

a) Processo de trabalho em saúde: O processo de trabalho vem sendo considerado como o componente fundamental sobre o qual a gerência deveria atuar se desejasse produzir mudanças (Campos, 1992, 1994; Merhy, 1997).

Há duas correntes bastante delineadas a respeito do processo de trabalho em saúde. Uma primeira ligada à continuidade do paradigma flexneriano de organização do trabalho médico, com versões mais ou menos aggiornattas, que influi na organização do trabalho do restante das profissões na saúde (as quais, nesse modelo, continuam sendo auxiliares) (Berliner, 1975). A outra grande corrente defende a reflexão crítica sobre o processo de trabalho em saúde, visando - com diversas ênfases - mudar a centralidade do saber médico na determinação dos processos de trabalho em saúde. Três autores que têm dado ênfases diferentes à questão: Ricardo Bruno Gonçalves (Gonçalves, 1988), Emerson E. Merhy (Merhy, 1997) e Gastão Campos (Campos, 1997).

Para Gonçalves (1988), são características fundamentais do trabalho humano a sociabilidade e a historicidade, porém, ainda de acordo com o autor, o trabalho está tão determinado que as possibilidades de mudança só estariam na política e não no próprio processo de trabalho. Para ele, a técnica não existe isolada de sua apropriação diferenciada pelos médicos, que detêm o controle dos momentos intelectuais do trabalho, o que garantiria pela divisão social do trabalho, o triunfo dos médicos (Gonçalves, 1992).

Merhy (1997) apontou que os constrangimentos das macrodeterminações não seriam impedimentos absolutos. Ancorado nos conceitos marxistas de "trabalho vivo e morto", enfatizou a capacidade e a potencialidade que os trabalhadores da saúde têm - até pela sua especificidade e controle das técnicas e saberes de utilizar parcelas maiores de trabalho vivo, criativo, o que, para ele, somente ocorreria em ato. Concordando, defendemos que o processo de trabalho em saúde é, e será sempre, singu- 
lar. Ainda quando a gestão e o planejamento criem "linhas de produção", elas operarão sobre o corpo, o psiquismo e a dor de alguma pessoa concreta, única.

Campos (comunicação pessoal) propôs um novo conceito para lidar com essas questões: o de "clínica ampliada", uma clínica singular, na qual "cada caso é um caso... mas consegue dialogar e incorporar criticamente outros saberes $e$ diretrizes", incorporando, assim, questões como o vínculo, a resolutividade e a responsabilização. $\mathrm{O}$ autor contrapõe esse conceito de clínica ampliada aos de clínica degradada (dos pronto-atendimentos, funcionando na lógica da queixa-conduta) e clínica tradicional (absolutamente autocentrada nos seus saberes privativos - e também privatizados). Achamos que a discussão a respeito dos modelos clínicos está profundamente imbricada com a questão do processo de trabalho e que o processo de trabalho em saúde tem a especificidade de só conseguir ser efetivamente transformado quando os paradigmas clínicos são questionados, reformulados e legitimados. Dessa forma, defendemos que a reflexão sobre processo de trabalho em saúde é sempre uma reflexão sobre o modelo assistencial proposto.

b) Campo e núcleo de competência e responsabilização: Campos et al. (1997) afirmam que a diferenciação de áreas de competência e de responsabilidades profissionais em campo e núcleo poderiam subsidiar uma série de negociações nas instituições de saúde. Campo de competência seria “(...) um espaço de sobreposição de exercício... ou seja, campo de interseção com outras áreas”, e o núcleo, mais específico, "incluiria as atribuições exclusivas" da especialidade em questão; "assim, o campo de competência teria limites e contornos menos precisos e o núcleo, ao contrário, teria definições as mais delineadas possíveis..." (Campos et al., 1997:143).

Utilizamos esses conceitos num sentido ampliado, já que os consideramos centrais também em relação às distintas disciplinas que compartilham o trabalho em saúde. Temos essa questão como particularmente importante na transformação do processo de trabalho, já que - acreditamos - a mudança implica diálogo/negociação. Esses conceitos são também particularmente interessantes de serem explorados em relação à saúde mental e ao caso em estudo, onde há equipes multiprofissionais vinculadas a Unidades de Produção desde 1990.

c) Conflito e consenso: Para grande parte dos sanitaristas latino-americanos, o conceito de conflito pressupõe uma disputa de (e pelo) poder: “(...) el reconocimiento del conflicto es un primer punto común que caracteriza el paradig- ma de la Planificación Estratégica" (Chorny, 1990:34), tanto que o termo estratégia, para esse autor, só teria sentido se houvesse conflito. Lechner (1981:51) afirma que conflito "não é tanto uma luta entre sujeitos, mas uma luta pela constituição de sujeitos, uma luta por ser reconhecido como sujeito (...)”. Testa (1997) defende que conflito não se expressa como discurso mas como ação, o que assinala os sentimentos - o sentido para ele - postos em jogo.

Em Matus (1993), a ênfase dada à colaboração e cooperação é pequena, e o outro é visto como um concorrente do jogo, no qual, por definição, alguns ganham e outros devem perder.

Por outro lado, na teoria sobre o agir comunicativo, o conflito é considerado como potencialmente negociável. Consideramos que essa teoria tem uma contribuição para a área do planejamento. Não só Testa (1993), como também Rivera (1995) atribuem ao planejamento um papel dialógico; ambos os autores enxergam o planejamento contribuindo para a ação comunicativa nos grupos. A inclusão dessa linha de análise pretendeu avaliar se o espaço das oficinas de planejamento constituiu-se efetivamente em um espaço dialógico ou se exacerbou conflitos.

\section{- Fase de reconstituição}

Nessa fase, utilizou-se outra série de categorias e conceitos para reconstituir uma interpretação do processo. Chamou-se a essas linhas de reconstituição, para distingui-las da noção de reconstrução, que seria voltar a construir o mesmo, igual ao que era: processo impossível, que paradoxalmente estaria negando a História, e o sentido, que nos propomos a resgatar. Como categorias de reconstituição ou síntese trabalhou-se com:

a) Mediação: Propunha-se a desvelar como o planejamento se constituíra em canal real de articulação da mudança, o que haveria ou não conseguido veicular, reconstruindo as redes dessa ponte que chamamos de mediação entre os espaços das políticas e as práticas.

b) Determinação/Condicionamento: Resgatou-se o par determinação/condicionamento (Testa, 1993) como vetor que expressa, em cada situação, uma complexa rede que entrecruza espaços, que pode assumir diferentes direcionalidades (seja vertical, horizontal ou transversal) e que pode atuar como força positiva ou limitante. Consideramos que no uso habitual desses termos perdeu-se a sua riqueza conceitual, aplicando-se o termo determinação, em geral, como linearidade causal exercida, do espaço macro em direção ao micro, com o que a 
explicação de muitos processos torna-se menos potente.

c) História/Tempo: Os processos levam tempo. As tecnologias de planejamento requerem um certo prazo de aplicação, entrando, assim, em conflito com a concepção imediatista de tempo político. As mudanças da cultura e da política institucional também levam tempo. É freqüente que processos de mudança não consigam se estruturar, no tempo, em um projeto durável.

Para Lechner (1990), quem quiser fazer algo necessita de tempo. Segundo o autor, os processos se desenvolvem nessa dupla tensão duração-tempo, já que somente com tempo as ações humanas adquirem forma, e as mudanças precisam se estruturar em uma ordem durável. Ainda de acordo com Lechner, o tempo é objeto de decisão política e não somente condição prévia para qualquer ação política: " $\mathrm{Ha}$ cer política implica estructurar el tiempo... No existe un tiempo único; hay tiempos, tiempos sociales..." (Lechner, 1990:63). Quem detém o poder pode organizar o tempo dos outros, ou seja, estabelecer prioridades.

Para Testa (1997), a história seria o tempo estruturado (num significado dado), e reconhece que a constituição de atores sociais é um problema histórico. Preferimos essas concepções de tempo/história a outras que somente tratam do tempo como um recurso (Matus, 1989).

\section{Resultados e discussão sobre as imagens-objetivo construídas pelas Unidades de Produção}

\section{Moradores}

Passou-se de uma enunciação muito vaga sobre a “ressocialização dos pacientes", em 1992, para se acrescentar, nos anos seguintes, a especificidade da abertura de moradias protegidas. Acrescentou-se também proposta de trabalho com famílias e passou-se a almejar que a Unidade fosse espaço de formação para os profissionais de saúde. Em 1994, desapareceu a frase: “impossibilidade de sair", impedimento que estava colocado como pressuposto, nas formulações anteriores, para um grupo de pacientes mais graves.

\section{Agudos}

Passou-se de uma formulação muito vaga atender pacientes agudos de modo que o retorno à família e à sociedade seja o mais breve possível - a definições mais precisas - atender pacientes em crise e ser referência para a rede pública de saúde mental. Entre 1995 e 1996, detalharam-se alguns aspectos relacionados ao modelo tecno-assistencial, como aqueles vinculados à remissão rápida de sintomas, à inclusão das famílias no projeto terapêutico individual e ao propósito de se constituir como centro formador e de pesquisa em saúde mental.

\section{Núcleo de oficinas de trabalho}

Nessa Unidade, as primeiras imagens-objetivo parecem mais ousadas que as últimas. Deixouse de querer ser um "equipamento auxiliar do SSCF e da rede" e uma "empresa social" com "atuação direta dos participantes na gestão", passando-se a propor oficinas específicas e prestação de serviços que deveriam propiciar a conquista da cidadania pelos pacientes. Todavia, foram desaparecendo a referência aos conceitos de empresa social e a autogestão dos usuários.

\section{Hospital-Dia}

As mudanças foram mais sutis, porém com o mesmo sentido. A primeira imagem-objetivo dava ênfase ao papel da Unidade como referência à rede básica e ao SSCF como alternativa à hospitalização. Além disso, propunha-se a ser um auxiliar na reformulação do SSCF, criando uma nova cultura psiquiátrica. Em 1995, queria exercer seu papel junto à rede básica e à Unidade de Agudos, a fim de diminuir o tempo de permanência dos pacientes. Nesses anos, mudou a redação das imagens-objetivo num sentido instigante: passou-se de querer ser um "espaço terapêutico alternativo à internação" a "espaço alternativo à internação psiquiátrica integral”. Parece-nos não ser a mesma questão.

As imagens-objetivo das quatro Unidades assistenciais sofreram modificações no percurso dos anos. Tais mudanças, em geral, têm a ver com uma definição mais precisa das diretrizes para o atendimento clínico, como também com uma ampliação do nível de abrangência dos diferentes modelos tecno-assistenciais propostos.

Se pensarmos as mudanças ocorridas nas imagens-objetivo como mudanças nos desejos, pareceria que estes cresceram nas equipes dos Moradores e Agudos e decaíram nas do Núcleo de Oficinas de Trabalho (NOT) e do HospitalDia. As Unidades de Moradores e Agudos eram as que carregavam o peso do velho; as outras duas foram criadas logo após o convênio de cogestão com a prefeitura. Não existiam antes, no Cândido sanatório; logo, não tinham o peso da história nas costas. O que haveria mediado, de 
modo diferente, numa mesma instituição, na mesma época? O contexto macro era o mesmo, a alta gerência também.

\section{Resultados e discussão sobre problemas/operações constantes nos planos das Unidades de Produção}

Em virtude das linhas de análise, o material empírico foi sistematizado da seguinte maneira: os problemas/operações foram distribuídos de forma temática, conforme fossem clara e facilmente identificáveis como referidos a processo de trabalho, campo/núcleo e/ou conflito/consenso. Observou-se que um número muito pequeno de problemas não cabiam claramente nessa matriz (menos de $10 \%$ ) e eram, em sua maioria, referentes a compra ou investimento em infra-estrutura, bem como contratação de pessoal ou serviços: esses problemas aparecem nos planejamentos como problemas estruturados. Posteriormente, foram classificados como referidos a campo e núcleo, por se considerar que remetiam à questão da autonomia das equipes. Esses critérios foram mantidos para a análise de todas as Unidades, em todos os anos.

A sistematização realizada permitiu a constatação inicial de que uma série de problemas reaparecia com variações mínimas, repetindose ano após ano. É essa uma questão instigante. Tais formulações repetiam-se até nas operações propostas em alguns casos: a reverberância desses problemas foi surpreendente. Dentre eles, o maior número correspondia ao processo de trabalho, e algumas Unidades demoraram anos para problematizá-lo, mas, quando isso aconteceu, foi sempre depois de uma reflexão sobre campo/núcleo.

Em várias das Unidades, coincidentemente, houve a seguinte aparição cronológica de categorias:

- Uma primeira reflexão sobre os campos/ núcleos de competência, elaborada de modo bastante genérico e se sobrepondo parcialmente à formulação das imagens-objetivo. Consideramos que, na definição de imagens-objetivo, dá-se o primeiro passo para a definição de campo e núcleo de responsabilidades e competências das equipes, mas, na qualidade de mediação, as imagens-objetivo - que estão, segundo Matus (1993), além do horizonte do plano - têm a potencialidade de ser mais do que isso; são projeção de rumo segundo diretrizes dadas.

- Uma segunda fase, na qual as equipes apareceram quase que naturalmente se debruçan- do sobre o processo de trabalho. Parecia coerente. Sabendo-se o que fazer, passou-se a pensar em como fazê-lo.

- Decorrente desse passo anterior, voltou à reflexão a questão do campo/núcleo, mas agora em relação a conflitos potenciais ou reais com os outros (ou fora da Unidade).

- Por fim, voltaram as questões sobre o processo de trabalho, repensando o campo/núcleo, dessa vez em relação ao interior da própria Unidade e à questão da multiprofissionalidade.

Algumas reflexões a respeito dessa seqüência empírica: primeiro, alertar que o jogo de negociações provisórias, defendido por Campos et al. (1997), que daria lugar a definições mais precisas sobre campo/núcleo, é complexo e demorado, requerendo das equipes um certo amadurecimento preliminar sobre o processo de trabalho. Deu-se a impressão de que as equipes não conseguiam fazer esse movimento sem antes acontecer uma certa estruturação do grupo como tal. Nesse sentido, consideramos que o uso proposital dos conceitos campo/núcleo no processo de planejamento poderia contribuir para a própria constituição do grupo com maior rapidez e clareza. Ou seja, sustentamos que a definição de um objeto de trabalho comum (o qual, no sentido ampliado que estamos dando aos termos, seria o núcleo da Unidade) poderia contribuir para a constituição da identidade dos grupos.

Parece-nos que somente depois disso as equipes conseguiam negociar os papéis dos seus integrantes no interior da Unidade, o que implicaria uma verdadeira abordagem da questão da multidisciplinariedade. Nesse momento, o que era o núcleo da Unidade se transformava em campo da equipe, reposicionando a discussão dos saberes. Esse seria o ponto de partida para o encontro e o diálogo criador de novos consensos. Partida na direção de um lugar no qual existiria espaço para a obra pessoal de cada um e, também, para dar conta do trabalho coletivo. A segunda reflexão que trazemos, com base nessas evidências empíricas, quer alertar sobre a inconveniência de se tentar forçar determinada seqüência de problemas e tarefas. No SSCF, houve uma tentativa de promover a discussão sobre o processo de trabalho a partir de 1995, porém isso não conseguiu evitar que grande número de problemas relacionados ao processo de trabalho continuasse reverberando e que a discussão sobre campo/núcleo voltasse à pauta. Assim, as dívidas anteriores ficaram reverberando, circulares, sem solução.

Debruçar-se sobre o processo de trabalho não resolve aquelas questões vinculadas à cla- 
reza sobre o rumo do projeto (diretrizes) ou de competência e responsabilização (campo/núcleo), nem a falta de constituição dos grupos como tais. Aliás, se novos saberes e propostas tecnológicas não mediarem, somente haverá uma reflexão reprodutora do status quo, que age no nível das faltas, mas faltas demais desse estado.

Consideramos que houve prejuízo para as equipes com a falta de uma análise histórica do processo vivido pela instituição, não ocorrendo, portanto, sua re-significação para o coletivo da organização: análise da complexidade foi perdida. A repetição, ano após ano, dos mesmos problemas e operações indicam o fato de o planejamento no SSCF ter-se ritualizado: o planejamento fetiche.

Segundo Matus (1993:23), "o plano é a mediação entre o saber e a ação". Assim, na escolha dos problemas e na elaboração das operações somente serão reconhecidos aqueles que combinem com o paradigma tecnológico vigente no grupo. O olhar dos atores é, sem dúvida, determinado pelo paradigma tecno-assistencial vigente. A questão que tentamos evidenciar aqui é a da possibilidade de um condicionamento, no sentido vertical, de cima para baixo, desde o plano dos saberes em direção à formulação do projeto e, obviamente, do recorte inicial dos problemas.

Perguntamo-nos, no caso em estudo, o plano foi mediação entre quais saberes e quais ações? Os saberes que direcionaram a mudança provinham fundamentalmente de dois campos: o da reforma psiquiátrica brasileira e de aspectos do modelo de gestão e atenção sugeridos pela corrente denominada Em Defesa da Vida (Campos, 1991). O desenvolvimento da maioria dos conceitos dessa corrente foi simultâneo com as mudanças no SSCF. Neste trabalho, queremos ressaltar que esse corpo de conhecimento em formação teve, também, um papel determinante nas mudanças propostas. Nesse diálogo, às vezes difícil, entre esses dois grandes grupos de diretrizes (o da reforma psiquiátrica e o da Defesa da Vida), é que se deve procurar aquele primeiro saber ao qual faz referência Matus, e que o plano, esperava-se, mediasse para a ação. A modelagem proposta para o SSCF tinha níveis de definição bem diferentes. A reforma psiquiátrica brasileira oferecia diretrizes muito genéricas que diziam muito mais respeito ao "que fazer" ou "ao que não mais fazer", do que ao "como fazê-lo". Entretanto, eram diretrizes muito potentes (às vezes, elas acabaram sendo onipotentes), decorrendo essa força toda, talvez, do fato de serem amplamente legitimadas e difundidas.
Já as diretrizes do modelo em Defesa da Vida se propunham, desde o princípio, a ser propositivas em relação ao "como fazer". Contudo, esses novos saberes careciam do peso e do consenso das diretrizes da reforma psiquiátrica.

A proposta de um modelo que tentava resgatar a clínica (Campos, 1994), em contradição com diretrizes nas quais a reinserção social era o eixo da cura, permeava, em grande parte, a numerosa referência a problemas sobre o processo de trabalho constatados no SSCF.

Esses saberes em pugna se articularam, em um primeiro momento do planejamento, e mediaram a formulação das imagens-objetivo. Em um certo sentido, as mudanças nas imagensobjetivo de cada Unidade, não só obedeceram a diferentes modulações do contexto, mas, também, refletiram as diferenças de hegemonia entre esses saberes. No espaço das mediações, perceberam-se linhas de determinação e condicionamento que se cruzavam, às vezes, no mesmo plano, confirmando que a determinação acontece não só na direção vertical, e de cima para baixo, mas como rede que entrecruza espaços.

Em relação à linha de reconstituição História/Tempo, observamos como é mais fácil a estruturação de um significado histórico na instituição quando referido a diretrizes potentes, e consensuais, como foram, no caso, as da reforma psiquiátrica, do que quando dizem respeito a outras menos legitimadas e potentes.

Queremos, neste momento, trazer à reflexão o papel das diretrizes em relação ao planejamento e aos processos de mudança institucionais, além do caso singular em estudo. Sem dúvida, trabalhar com diretrizes é um recurso muito potente, no sentido de que elas permitem confrontar, a todo momento, o plano com "algum rumo". O uso das diretrizes dessa maneira está, poderíamos dizer, mais para o Pensamento Estratégico do que para o Planejamento Estratégico Situacional; mais para direcionar projetos e processos - diria Testa - do que para propor receitas. Mais voltado à construção de sentido e mudança de cultura institucional do que à operacionalização instrumental.

Quando Matus coloca que o "plano é a mediação entre saber e ação", ele está pensando em um saber homogêneo, ou pelo menos hegemônico para o grupo no governo, que é anterior ao plano, é um "dado saber". Contudo, achamos que essa situação é rara em casos de intervenção institucional, e mais ainda no campo da saúde. As instituições estão atravessadas por saberes contraditórios ou até antagônicos, e esse é um problema que o planejamento tradicional não se propõe a resolver. Para os planejadores clássicos, essa é uma etapa anterior 
ao planejamento, o mesmo não acontecendo, contudo, com o Pensamento Estratégico, desde que a teoria é determinante do Método no Postulado da Coerência de Testa (Testa, 1993).

Consideramos central a questão de manter o planejamento como um instrumento que visa à operacionalização de ações, contudo pensamos que incluir a discussão e reelaboração de diretrizes dentro do processo de planejamento permitiria confrontar o plano com os fins da instituição a cada momento. A apropriação de diretrizes pelos grupos é um processo demorado, reflexivo e, achamos, deveria sempre pressupor direito à apropriação crítica. O que defendemos, ancorados na evidência empírica do caso em estudo, é que o planejamento, se saísse de seu enquadramento clássico, teria capacidade para subsidiar processos de tradução de diretrizes. Que queremos dizer com isso? Parece-nos evidente que, por exemplo, vínculo e resolutividade não podem significar o mesmo para uma Unidade de Agudos e para um Hospital-Dia, questões para as quais o planejamento poderia contribuir muito para clarear, potencializando, com sua lógica mais operativa, a capacidade das equipes intervirem no desenho das próprias Unidades.

No presente estudo, constatamos o peso das diretrizes da reforma psiquiátrica. Como exemplo disso, observamos a Unidade de Agudos se debruçando "loucamente" e de maneira reverberante sobre o processo de trabalho, por não ter conseguido relativizar a diretriz da reforma psiquiátrica - desinternação -, que a condenava à desaparição. E o Hospital-Dia demorando anos em problematizar o processo de trabalho (o que estaria errado se era a mais antimanicomial das Unidades?). Peso onipotente das diretrizes que o planejamento não conseguiu diminuir.

Se pensarmos o planejamento como um dispositivo que deveria contribuir para a reflexão crítica, com base na qual seria possível encarar a construção coletiva do futuro, parece-nos que, no presente caso, o planejamento não conseguiu desempenhar esse papel. Assumir essa questão significa também, portanto, questionar a onipotência tecnocrática do planejamento e recolocá-lo - no espaço de mediação - junto com outros dispositivos viabilizadores de mudança.

Propomos pensar o planejamento como dispositivo capaz de subsidiar a construção de subjetividade e não aceitar mais a sua tradicional posição de dispositivo de controle, destinado a enquadrar os trabalhadores.

Se o planejamento teve todos estes limites que estamos colocando, o que mais haveria mediado a mudança? No caso em estudo, outros dispositivos, sem dúvida, também sustentaram a mudança de modelo: gerência colegiada, Unidades de Produção multiprofissionais, supervisões etc. Nas limitações identificadas no planejamento, achamos evidências - indiretas - de que houve outros dispositivos com potencialidade mediadora.

Então, qual foi o resultado positivo do planejamento? Mesmo algumas das questões criticadas têm seu lado positivo. A compulsão pelo agir, que criticamos quando constrangedora e limitante da reflexão, tem sido no SSCF, achamos, uma das chaves para quebrar a rigidez estrutural do manicômio. Durante os anos analisados, o planejamento constituiu o espaço deliberativo por excelência da instituição. Sendo assim, o planejamento foi um dos dispositivos privilegiados para a participação. Para Testa, o planejamento possui outras funções, como as de estimular o crescimento, criar possibilidades de mudanças e estruturas comunicativas (Testa, 1993). Concordando, consideramos que o planejamento contribuiu para a mudança institucional no SSCF, tendo-se perdido, talvez, no caso em estudo, fundamentalmente, o "pé" histórico-crítico desse processo defendido por Testa; "pé” que esperamos haver contribuído para restituir, com este trabalho, pelo menos em parte.

\section{Esboço de uma nova proposta}

Um planejamento que desse conta de promover mudanças em serviços de saúde não seria, então, uma receita pronta. Nem devedor de uma metodologia só. Seria dispositivo, agenciador, analisador, enfim, permanente movimento. Espaço de troca e de participação. De fala protegida e de organização. De operacionalização e também de reflexão crítica. Não seria determinista, casuísta, nem linear, mas analítico. Mais perguntaria que responderia. Todavia, não faria só perguntas ingênuas, afinal, o planejamento trabalha com fins, sentidos. Faz perguntas dirigidas ao rumo das diretrizes e à transformação. Subsidia o crescimento e subverte a ordem de poderes estabelecidos. Mas, formula um "para quê" inicial, que o antecede. Tem propósitos explícitos. Presta conta e aceita prazos para os desafios, ou, pelo menos, desafia-se com prazos. Ele detém uma certa capacidade de organizar os grupos para a ação. Não perde a sua potência instrumental, só que essa deixa de ser sua única lógica. Ele segue, também, uma lógica analítica, necessária para o amadurecimento e constituição dos grupos que 
planejam. O planejamento que propomos implica certos saberes que estão além dos métodos prontos, sem que com isso queiramos desconhecer a importância de se trabalhar competentemente com questões metodológicas.

O planejamento que propomos precisa ser instituído ainda. Das agências oficiais de governo até o menor dos centros de saúde, há muito plano linear e esquemático, pretendendo dar conta de questões complexas. Os problemas quase estruturados, que Matus se propõe a resolver, são só uma parte da leitura da complexidade do mundo real; eles são, também, "recortes". Essa proposta metodológica visa abordá-los somente a partir da racionalidade. Está aí o seu limite. Quando Testa polemiza com Matus sobre a necessidade de colocar o Método de Planejamento em situação histórica, abre o caminho para esta reflexão.

De Freud até hoje, quase ninguém acredita que o mundo, os problemas, as coisas, possam ser explicadas simplesmente pela razão. Vivemos em espaços subjetivos, permeados pelo encontro e desencontro de subjetividades, valores, crenças. O planejamento, por mais estratégico que se pretenda, não poderá dar conta nunca dessas questões desde certa linearidade racional. Não que achemos que o planejamento seja "a receita" para dar conta da subjetividade nas organizações, mas, sim, acreditamos, que ele não pode mais continuar surdo a essa importante questão. O planejamento como dispositivo, que aqui estamos propondo, seria mais um espaço para a subjetividade aparecer. Quem trabalhasse com planejamento, em qualquer instituição, deveria incorporar entre os seus saberes a capacidade da escuta. Não só ouvir. Escuta aprimorada daquilo que, às vezes, fala em silêncio. Tampouco estamos propondo que o planejador seja um megaassessor, nem que vire psicanalista. De novo, saber composto, dialógico, fragmentado e limitado, mas que vai ao encontro dos outros.
Tentamos, aqui, colocar algumas propostas no intuito de contribuir para uma reflexão sobre o campo do planejamento, formuladas, porém, considerando-se as conclusões do caso singular em estudo.

Achamos que algumas das críticas formuladas ao planejamento, neste trabalho, poderiam ser igualmente levantadas tendo como base o estudo de outros casos singulares. Já é quase senso comum para grande número de assessores de planejamento que as oficinas produzem o que já sabemos que produzirão em termos de planos. Então, para que fazê-las? Isso reforça nosso argumento sobre o fato de que o mais importante produzido nas oficinas de planejamento não são somente planos. Coisas acontecem com as pessoas nesses encontros. Contratos se estabelecem. Prioridades são explicitadas.

Desejamos, também, ressaltar a riqueza analítica de se estudarem tecnologias no espaço de mediação. As "falhas" do planejamento detectadas no presente estudo só puderam ser percebidas quando colocadas num contexto histórico, metodológico e institucional singular. Qualquer planilha de planos do SSCF analisada isoladamente poderia subsidiar, no máximo, uma crítica à metodologia empregada. Tentamos outra tarefa: recuperar, valendo-nos dos documentos do planejamento, uma parte do discurso institucional e, com base nesse discurso, reconstituir um pedaço da história institucional. Tarefa possível em virtude do posicionamento - no espaço intermediário - que tentamos manter ao longo da pesquisa.

Espaço de mediação, espaço do devir dos processos, nos quais estaria escondido o segredo da eficácia das atividades (Testa, 1992) e a possibilidade de perceber que, por fortuna, o mundo ainda está cheio de segredos, de labirintos que esperam que nos internemos neles.

\section{Agradecimentos}

A autora agradece à Fundação de Amparo à Pesquisa do Estado de São Paulo pelo financiamento da pesquisa e ao Serviço de Saúde Cândido Ferreira por ter acolhido esta pesquisa. 


\section{Referências}

BERLINER, H. S., 1975. A larger perspective on the Flexner report. International Journal of Health Services, 5:573-592.

CAMPOS, G. W. S., 1991. Saúde Pública em Defesa da Vida. São Paulo: Editora Hucitec.

CAMPOS, G. W. S., 1992. Reforma da Reforma: Repensando a Saúde. São Paulo: Editora Hucitec.

CAMPOS, G. W. S., 1994. Considerações sobre o processo de administração e gerência de serviços de saúde. In: Planejamento Sem Normas (G. W. S. Campos, E. E. Merhy \& E. D. Nunes, org.), pp. 932, São Paulo: Editora Hucitec.

CAMPOS, G. W. S.; CHAKOUR, M. \& SANTOS, R., 1997. Sobre especialidades médicas e estratégias para integrá-las ao Sistema Único de Saúde (SUS). Cadernos de Saúde Pública, 13:141-144.

CHORNY, A., 1990. Enfoque estratégico para el desarrollo de recursos humanos. Revista Educación Médica y Salud, 24:27-51.

GONÇALVES, R. B., 1992. Processo de Trabalho em Saúde. Cadernos Cefor. São Paulo: Secretaria Municipal de Saúde de São Paulo.

LECHNER, N., 1981. La Conflictiva y Nunca Acabada Construcción del Orden Deseado. Santiago de Chile: Siglo XXI Editores.
LECHNER, N., 1990. Los Patios Interiores de la Democracia. Santiago de Chile: Editorial Fondo de Cultura Económica de Chile.

MATUS, C., 1989. El Plan como Apuesta. Caracas: Fundación Altadir.

MATUS, C., 1993. Política, Planejamento \& Governo. Brasília: Instituto de Pesquisa Econômica Aplicada.

MERHY, E. E., 1997. Em busca do tempo perdido: A micropolítica do trabalho vivo. In: Agir em Saúde (E. E. Merhy \& R. Onocko, org.), pp. 71-112, São Paulo: Editora Hucitec.

RIVERA, F. J. U., 1995. Agir Comunicativo e Planejamento Social. Rio de Janeiro: Editora Fiocruz.

TESTA, M., 1992. Salud Pública Acerca de su Sentido y su Significado. Washington, D.C.: Organización Panamericana de la Salud.

TESTA, M., 1993. Pensar en Salud. Buenos Aires: Lugar Editoral.

TESTA, M., 1995. Pensamento Estratégico e Lógica de Programação: O Caso da Saúde. São Paulo: Editora Hucitec/Rio de Janeiro: ABRASCO.

TESTA, M., 1997. Saber en Salud. Buenos Aires: Lugar Editoral. 